\title{
The geographical report tool: a Web application to help in planning and to reach the objectives of the Mexican water policy
}

\author{
H. Sanvicente-Sánchez ${ }^{1}$, Y. Solís-Alvarado ${ }^{1}$, J. García-Hernández ${ }^{2}$ \\ \& R. Melgar-García ${ }^{2}$ \\ ${ }^{1}$ Subcoordinación de Planeación Hídrica, \\ Instituto Mexicano de Tecnología del Agua, México \\ ${ }^{2}$ Independent Consultant, México
}

\begin{abstract}
The Mexican Institute of Water Technology (IMTA) has developed a data warehouse (DWH) and a geodatabase (GDB) for the National Water Commission (Conagua) which contains all the information that has been collected and published over more than one decade in the books Water Statistics in Mexico and Water Maps Collection. Both DWH and GDB have information about social, economic and environmental aspects; the three pillars of sustainable development. DWH and GDB are linked through an identifier code (ID), which allows that any statistical information can be spatially mapped through a geographical layer. The DWH-GDB link is exploited by the geographical report tool, which permits a user to make a query and shows the result on a map. The query can mix any social, economic or environmental information related with a spatial feature, like states, counties, reservoirs, monitoring point, etc. and the map is created online in a dynamic way. The geographical report tool may build simple or complex queries using logical connectors. All the query information is integrated into the layer attribute table and a shapefile layer can be downloaded. The geographical report tool is a web application used through a username and password on the Internet. The system was integrated to help in planning and to reach the objectives of the national water policy summarized in: (i) sustainable development searching; (ii) integrated water management; (iii) achieve the objectives of planning in 2030. Keywords: water resources management, dynamic web geographic information system, sustainable development, water planning, water statistics mapping.
\end{abstract}




\section{Introduction}

Worldwide, water is recognized as the engine of life and over this concept the integrated water resources management (IWRM) tries to ensure the integrity of ecosystems and balance the use of water resources in different human activities such as growing food, power generation, production of all types of goods and services and social development. The population has grown along with the increasing competition for freshwater and has culminated in unprecedented pressures on water resources, making it necessary that countries have the accounting of water resources to avoid facing water shortages and restrictions in their economic and social development [1-3].

Since 1994, Mexico has had the National Water Act (LAN) [4] which states that water planning and programming must be supported by an information network and that the basis of the national water policy is the IWRM. The National Water Commission (Conagua) holds the water management.

The "Conagua" has been publishing since 1999, first the Basic Compendium of Water in Mexico (CBAM, 1999; 2001; 2002) and after that Water Statistics in Mexico (EAM, 2003; 2004; 2005; 2006; 2007; 2008; 2010; 2011; 2012; 2013; 2014) [5] which have become a national reference. EAM content combines water information with social and economic data. Another important publication is the Water Maps Collection (AA, 2008; 2010; 2011; 2012; 2013, 2014) [6], which has the objective to show the water information in a spatial way.

The annual EAM and AA actualization was going to be done using traditional method as Excel spreadsheets capture and edit, DBF tables (DBF files) and access database. The geographic information was managed in shapefile covers. However, the different formats and platforms (Excel and Access), the isolated files management and the growing information made it hard to have total control and useful information in a specific moment.

The IWRM, the evaluation and monitoring of water resources and their use focuses that water statistics could be improved, that they are based on concepts, definitions and coherence terminology and that they are better integrated with the economic, social and environmental statistics $[2,3]$.

Due to the problems mentioned and following the IWRM framework, in 2010 the Mexican Institute of Water Technology (IMTA) signed a contract with Conagua to develop an informatic system. It had to be actual and modern and contain all the CBAM, EAM and AA information. The informatic system works on the Web and it was given to Conagua at the beginning of 2013. One of the system tools is the geographical report tool, which lets statistical information be mapped spatially. We are going to talk about the geographical report in this paper.

\section{Geographical report tool}

The geographical report tool is a web application that allows the user to make a database query and shows the result on a map. The query can mix any social, economic or environmental information related with spatial features: like states, 
counties, reservoirs, monitoring point, etc. and the map is created online in a dynamic way.

The geographical report tool exploits a link that exists between a data warehouse (DWH) and a geodatabase (GDB), both created from CBAM, EAM and AA publishing.

\subsection{Database}

The Mexican Institute of Water Technology (IMTA) has developed a data warehouse (DWH) and a geodatabase (GDB) for the National Water Commission (Conagua) which contains all the information that has been collected and published over more than a decade in the books Basic Compendium of Water in Mexico (CBAM), Water Statistics in Mexico (EAM) [5] and Water Maps Collection (AA) [6]. It must be said that CBAM and EAM are related to the same kind of publishing, the first one was substituted by the second one. Actually, just EAM and AA are published.

The EAM has water statistic information which permits to generate time series that are the base of the DWH and the AA has a collection of public cover maps created by Conagua using an internal ArcGis GDB called working GDB.

It must be said that the times series stored in the DWH have different start date, because from the first publishing of the CBAM Conagua has always tried to collect old information to show tendencies and the evolution of variables along the time. For example, some variables in the DWH have information from 1900, but other variables from 1990 and a few from 1999 and newer.

Following a software engineering process the steps that were done to develop the database (which integrates the geographic, GDB, and the statistic, DWH, information) and the consulting interface were [7]: i) Conceptual design; ii) Database creation and programming; iii) Testing; iv) Documentation.

The conceptual design is the most important step because it is composed of requirements analysis, analysis of development platform and technology infrastructure on which the system is going to run and the interface requirement to exploit the database.

In general, the information in EAM and AA publications is grouped as follows:

- Geographical and socio-economic context;

- State of water resources;

- Uses of water;

- Hydraulics infrastructure;

- Water management tools;

- Water, health and environment;

- Future scenarios;

- Water in the world.

The database mind model (Figure 1) is visualized as a disc composed of three major parts, one for each axis of sustainable development (economic, social and environmental). Each major part is integrated by sections (systems) that grouped the information on a theme (e.g. for environmental axis will have the atmospheric, aquatic and terrestrial systems). Also like any disk it has sectors established 
through concentric rings defining levels of organizational hierarchy ecosystem (basin, hydrologic region, country and world) and finally, planning objectives to 2030 form a third dimension that establishes information relationships that must be taken into consideration in order to achieve them.

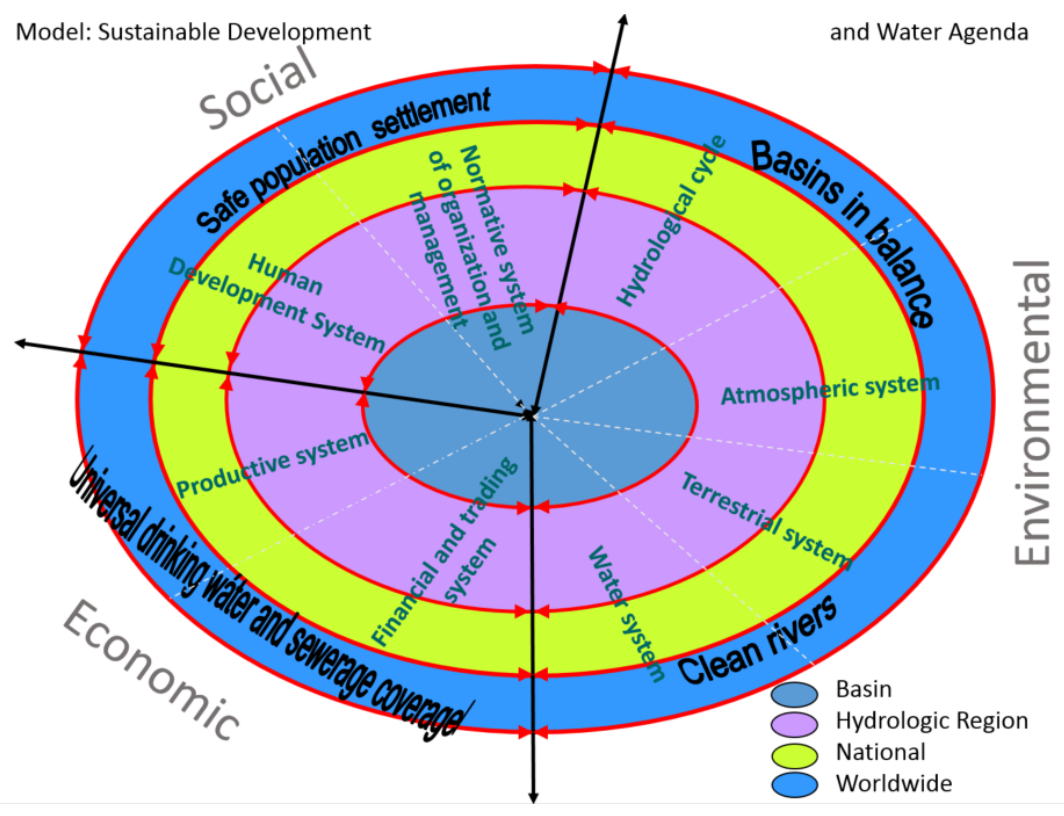

Figure 1: Database mind model.

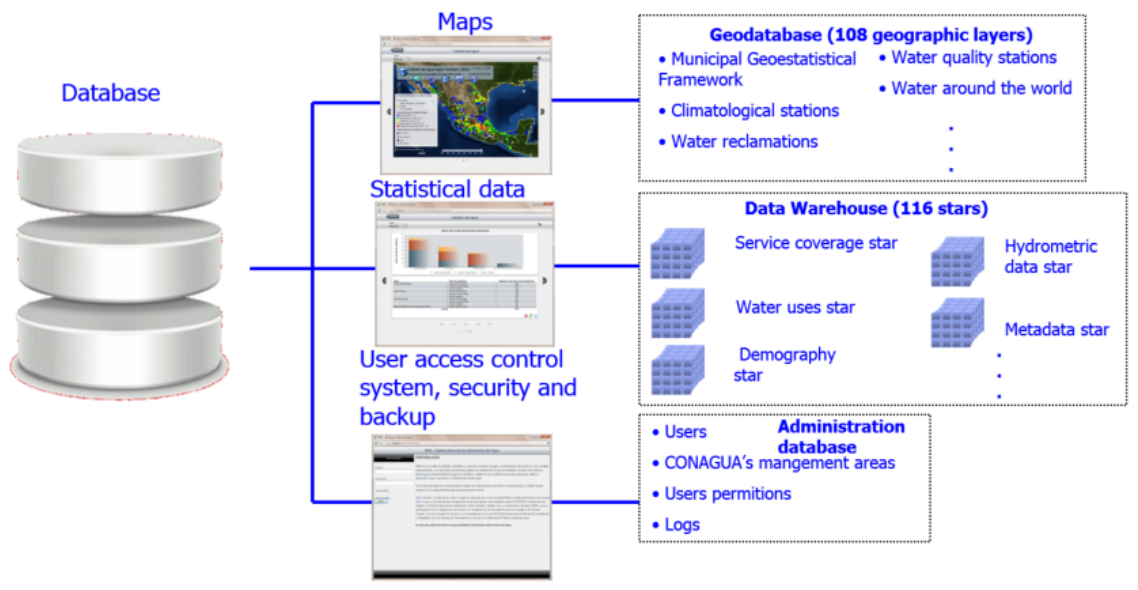

Figure 2: Database content.

With the mind model, the database's logical and physical designs were done and it was created. The database is integrated by the geodatabase (GDB), the data warehouse (DWH) and control and administrative tables (Figure 2). 
DWH and GDB are linked through an identifier code (ID), which allows that any statistical information can be spatially mapped through a geographical layer. The DWH-GDB link is exploited by the geographical report tool, which allows a user to make a query and shows the result on a map.

\subsection{Geographical report tool interface}

The geographical report tool is a web application, in Spanish, used through a username and password (Figure 3). Conagua staff through an email request provides the username and password. Figure 3 shows the login screen, which provides an overview of the information contained in the database. Besides there are links that will allow you to change your password or recover it if was forgotten.

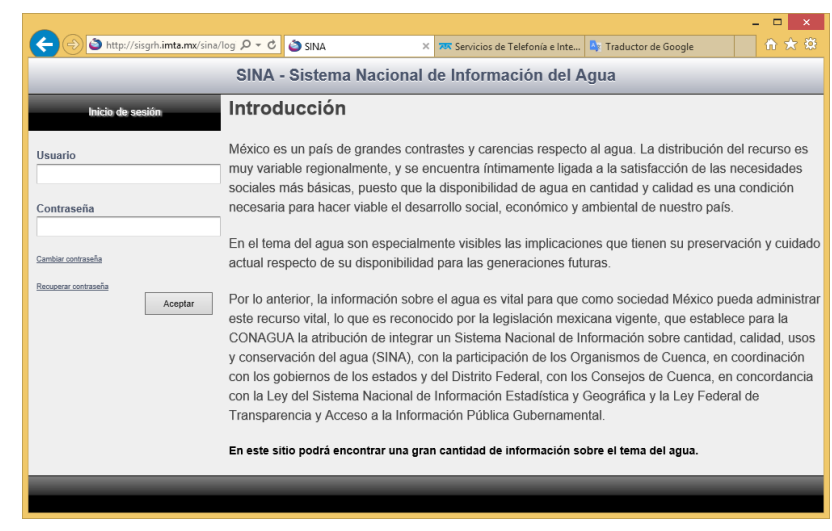

Figure 3: Login screen.

Once registered, an alert screen is displayed, it shows how updated is the information in the database. In the bottom, clicking the third icon, it will be highlighted and the geographical report tool web application will be shown (figure 4).

To facilitate the interaction with the user, the dialog box is divided into seven sections or steps that the user must follow and those are:

1. Select geographic layer;

2. $\quad$ Add the topics to consult (Add tables to query);

3. Select the fields to get for the selected topics;

4. Add filter conditions (use the "And" and "Or" buttons depending on the condition);

5. $\quad$ Choose the field that will be used to paint the map;

6. Set the symbology;

7. Save, retrieve or clear the report to a new query. 


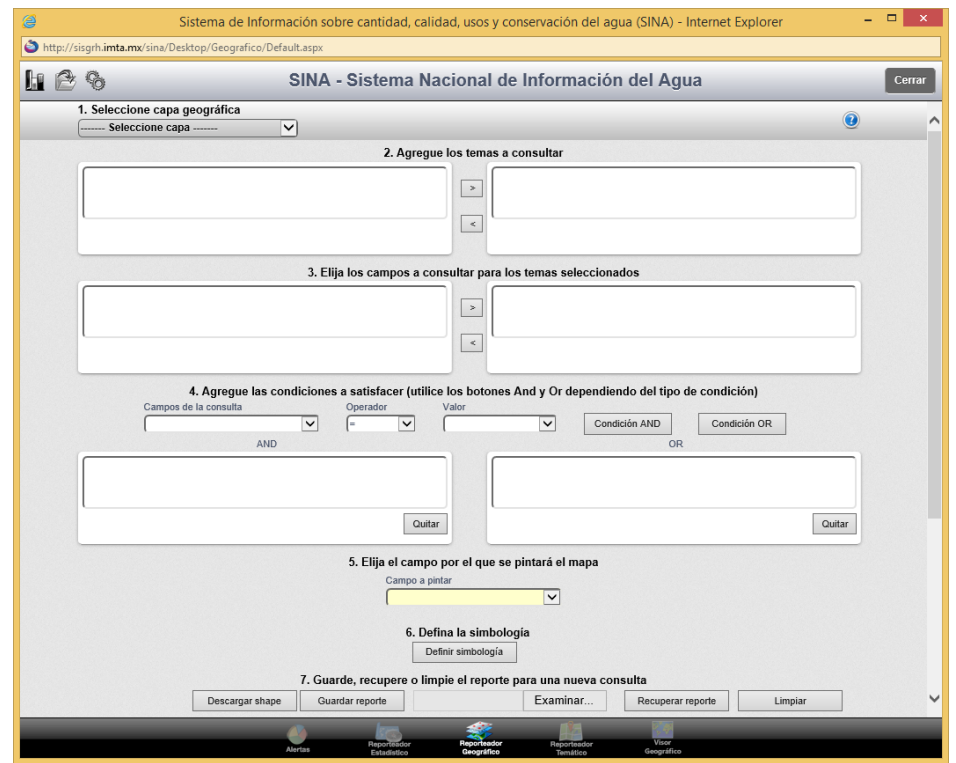

Figure 4: Geographical report tool screen.

To show how to work with the geographical report tool, we are going to answer the next question:

\section{Population with drinking water for municipalities with town size less than 15,000 inhabitants and its relation to the marginality index?}

First step, select the municipality layer from the dropdown list of section 1. All subjects with information from the database that can be mappable at the municipal level are automatically loaded into the left box section 2 (Figure 5).

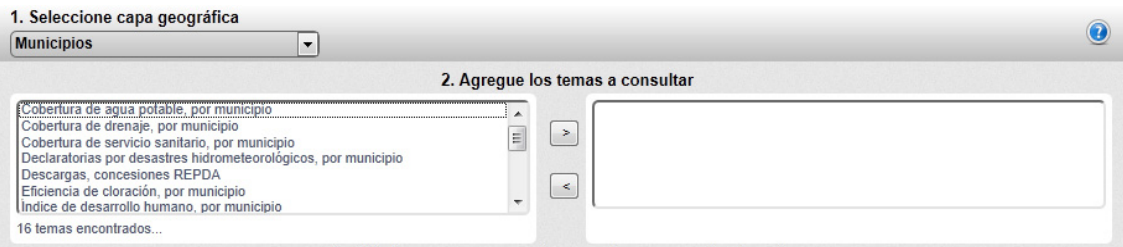

Figure 5: Municipality layer and its associated topics.

Second, sent topics of which you have a query, into the right box section 2: "Drinking water coverage by municipality" and "Marginalization rate and related variables, by municipality". Clicking on a topic in the right box (section 2) fill the left box section 3 with the fields of the table associated with the topic. 
Third, select from "Drinking water coverage by municipality" the fields: Municipality, Population, Town size, Supply form and Five-year. And from "Marginalization index and related variables, by municipality" the fields: Marginalization index and Place in the national context (this field as information of interest just).

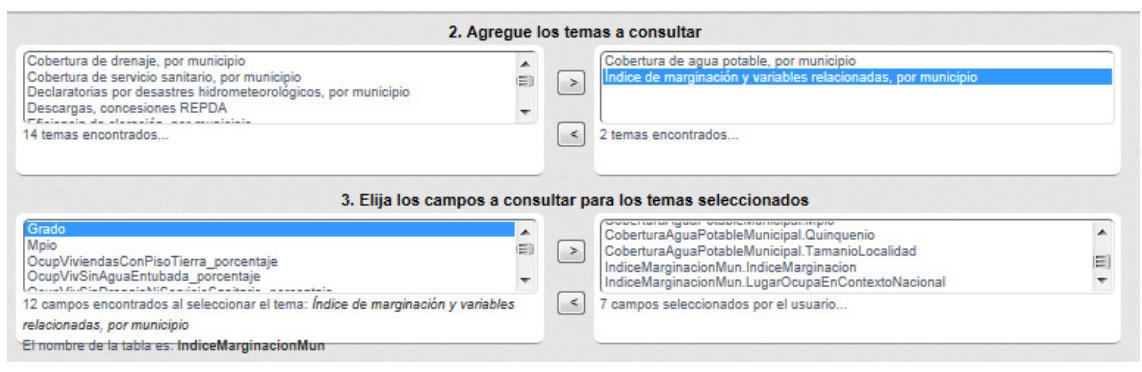

Figure 6: Drinking water coverage and marginalization index fields.

Step 4 the filter conditions that we need to do are:

1. Supply form $=$ "CONAGUA coverage"

2. $\quad$ Town size $=" 1-2,499 "$ OR Town size $=" 2,500-14,999 "$

Supply form is related to drinking water and stablish the type of coverage of water having a housing (values are: inside the house, outside the house but within the grounds, public hydrant, another home, without public network, unspecified, Conagua coverage). The "Conagua coverage" value is a simply grouping of several of these coverages and in our case it is the coverage of interest. For Town size, it is a text field then we need to make the filter condition as it is shown in numeral 2.

In the previous steps, we defined the query, now we need to choose the field that will be used to paint the map, this is done by the "Field painting" dropdown list that displays all fields selected in section 3. In this example, we are going to select marginalization index.

Now we need to define the symbology that is going to be used to display the map, to do this press the button "Define symbology" (Figure 4). A floating module will be opened (Figure 7) that will allow us to establish ranges of values and colors to paint. Ranges can be changed using the dropdown list labeled "Number of ranges" or changing the values directly into the editable boxes. The colors are changed by clicking the color box to be modified and then selecting a color or gray level of the box in the upper right corner. You can get an automatic ramp modifying the start and end colors and pressing the "Generate Colors" button.

Once the symbology has been established, press the label "View map" to display it. Because the map is dynamically generated online, the time to display it depends on the size of the query and the number of elements in the selected layer. Figure 8 shows the map for the symbology given in Figure 7. 


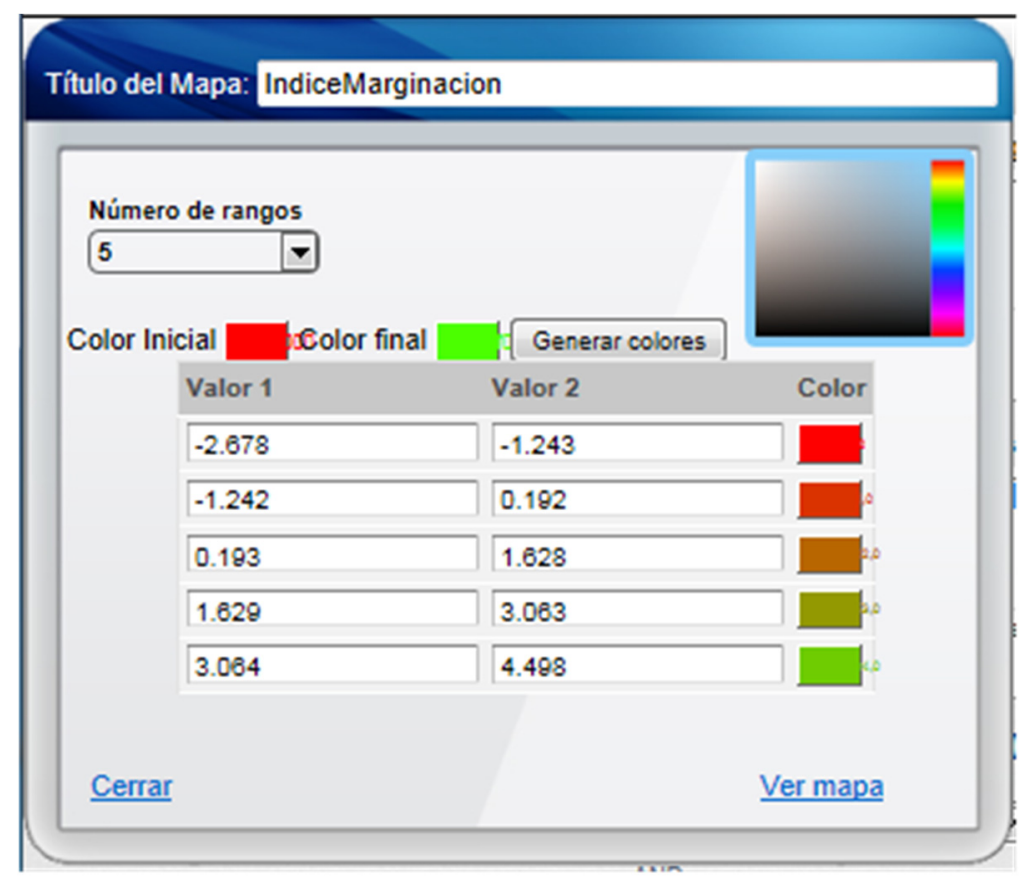

Figure 7: Module to edit symbology.

The query information for a municipality of interest is gotten by clicking on it. Also you can make zoom and pan and the toolbar has the option to return to the original zoom.

As shown in the Tooltip of Figure 8, the Five-year information is from 19861990. Since the field is not restricted, then the query retrieves the first record found, i.e. the value of 1986-1990 that is the first record stored in the database for the Five-year field. The ideal here is to restrict the Five-year field to ensure the display of adequate information temporarily.

In section 7, we can save the map by pressing the "Download shape" button, in this case, all the query information is integrated into the layer attribute table and a shapefile layer is downloaded. Pressing the "Save report" button" a text file with the query is saved. We can recover a report by selecting a text file with a query and clicking the "Retrieve report" button and finally clear the report pressing the "Clean up" button.

\section{Conclusions}

The geographical report tool was integrated to help in planning, decision making and reach the objectives of the national water policy summarized in: (i) sustainable development searching; (ii) integrated water management; (iii) achieve the objectives of planning in 2030. 


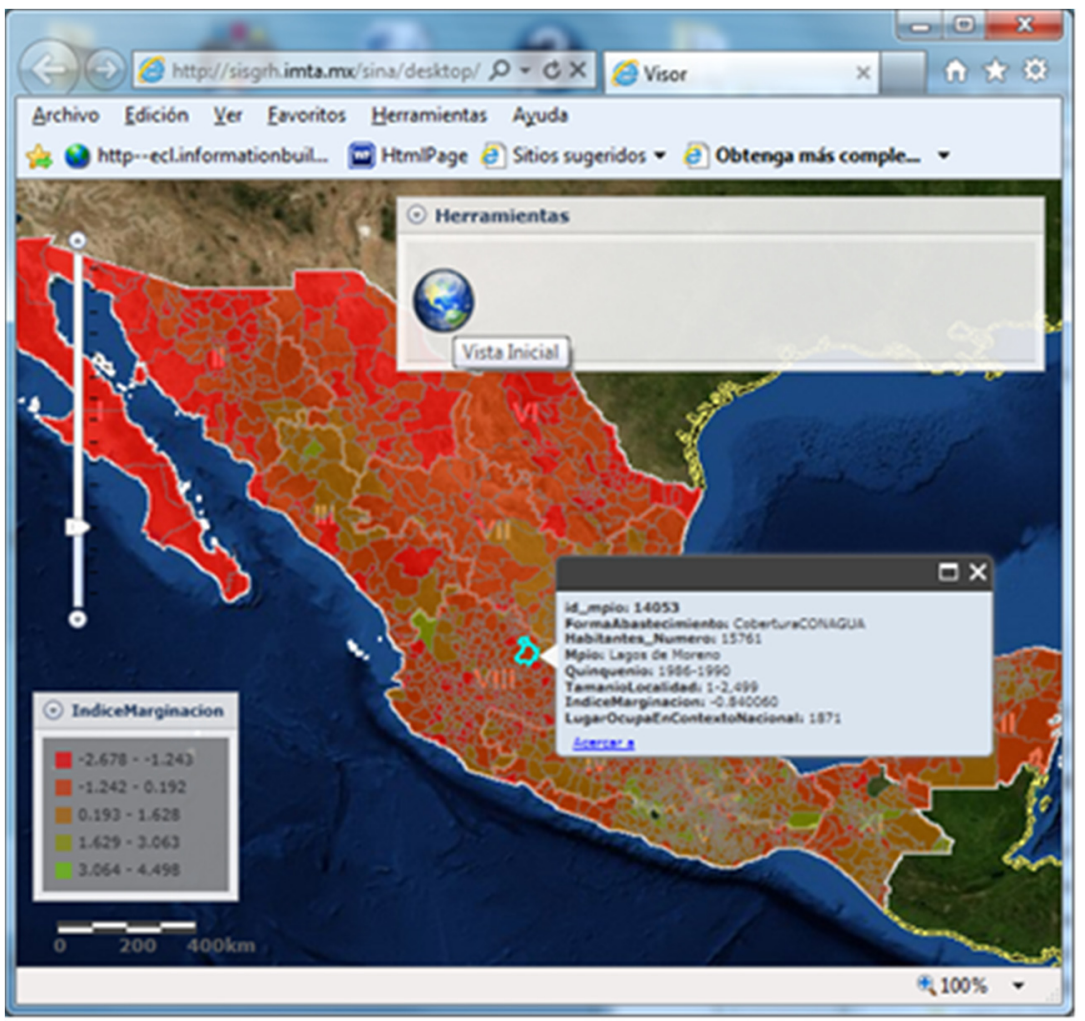

Figure 8: Map displaying using the geographical report tool.

Because all the database information is the official information published the EAM and AA book series. The geographical report tool is useful for performing diagnostics and analysis that combine environmental, social and economic aspects, the three pillars of sustainable development. The analysis can be done at different levels of aggregation, basin, municipalities, states, hydrologic, region, national and worldwide. The analysis for worldwide is restricted for some countries and variables.

As the geographical report tool exploits the DWH-GDB link, which allows that any statistical information can be spatially mapped through a geographical layer, all the analysis can be done considering the time, spatial and values variables (a multidimensional analysis).

\section{References}

[1] UNESCO-WWAP and UNSD. Marco para el Monitoreo de las Políticas Hídricas. Nota Informativa. CEPAL translation from the original publication of World Water Assessment Programme, Italy/New York, 8 pp., 2012. 
[2] UNSD. SCAE_Agua, Sistema de Contabilidad Ambiental y Económica para el Agua. United Nation Statistic Division, United Nation Publishing 0937623-2013, New York, 215 pp., 2013.

[3] UNSD. Recomendaciones Internacionales para las estadísticas del agua. CEPAL translation from the original publication of United Nation Statistic Division, New York, 235 pp., 2011.

[4] DOF. Ley de Aguas Nacionales. Diario Oficial de la Federación, Cámara de Diputados del H. Congreso de la Unión, México, 107 pp., 2013.

[5] Conagua. Estadísticas del Agua en México edición 2014. Comisión Nacional del Agua-SEMARNAT, México, 239 pp., 2014.

[6] Conagua. Atlas del Agua en México 2014. Comisión Nacional del AguaSEMARNAT, ISBN: 978-607-8246-76-2. México, 139 pp., 2014.

[7] Pressman, R.S. Ingeniería de software, un enfoque práctico. McGraw Hill. México, 206 pp., 2003. 